\title{
CPD BUT NOT AS WE KNOW IT
}

The BDJ Upfront section includes editorials, letters, news, book reviews and interviews. Please direct your correspondence to the News Editor, Kate Quinlan at the BDJ, The Macmillan Building, 4 Crinan Street, London, N1 9XW or by email to k.quinlan@nature.com

Press releases or articles may be edited, and should include a colour photograph if possible.
Stephen Hancocks OBE

Editor-in-Chief
A though I haven't checked, I suspect that as a single subject I have written more editorials on continuing professional development (CPD) than any other issue. The reason that this is yet another is because the General Dental Council (GDC) currently has a consultation paper out with proposals for new CPD regulations and requirements for what they now call 'CPD for dental professionals' and I urge readers to access these documents, consider them and respond by the deadline, which is Friday 21 March 2014. ${ }^{1}$

There are various proposed changes to the current system the most significant of which are a reduction in the overall hours required for each dental professional group, including dentists; that in future all CPD will have to be verified; and that every registrant will be required to have a personal development plan. There will also be a proposed interim period during which all dental professionals from the 15 time-cycle cohorts will all have different CPD requirements which should be fun as well as being a cinch to administer for us all.

I am sure that any good educationalist worth their salt will testify that personal development plans are good things, and rather like the concept of CPD itself, it would be difficult to disagree in principle. Indeed, as compared to having what might be termed directionless study such a plan sounds like a very reasonable option. But, when it comes down to it, for the vast majority of general dental practitioners of what would such a plan consist? I'm not trying to be difficult or cynical, I am just not sure of the answer and I suspect many readers may be equally bemused, at

\section{'Surely it is \\ what any \\ caring, con- scientious \\ profes- \\ sional does anyway?'} \section{.

.

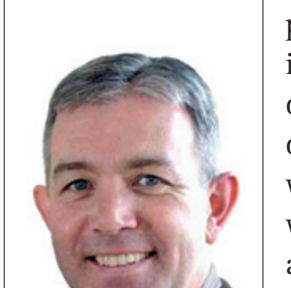

least at this stage. The GDC provide some stipulations to help here in that the CPD activity must conform to their 'standards'. These are contained in the documents quoted above and on the GDC's website (www.gdc-uk. org). Without the space to copy them here in full they include such universally applicable phrases as 'effective communication with patients, the dental team and others...effective management of oneself, and effective management of, or work with, others in the dental field...maintenance of development and knowledge'...and so forth.

Frankly, this simultaneously tells us everything and nothing. Surely it is what any caring, conscientious professional does anyway? However, in future we will be expected to detail what CPD we are intending to do to accomplish this plan, what CPD we have done to fulfil it and add to which of the criteria indentified each activity applies. It seems like a lot of words to me.

The removal of "non-verified' (ie self-attested) CPD is arguably a step in the right direction in that it apparently closes a loophole that is often identified as a meaningless measure. This is despite the fact that in my view the vast majority of dentists undertake such activity anyway and all but sub-consciously in keeping up to date and honestly applying that which they learn to their patient care and practice.

All that said, there remains the lingering doubts that however much more robust this new system might be in its capacity to reassure the GDC that they can point to documen- tary evidence of compliance, in terms of protecting the public, there is, I submit, little further proof that any dental professional will necessarily learn more, be motivated more or change their pattern of practice more than under any other system. And I believe this applies not only to us but to any professional or non-professional in terms of genuinely of itself providing definitive lifelong learning.

This is undoubtedly not the final editorial on this subject and the most insightful comment I think I can make, obvious as it may seem, is that we still are at the very beginning of this long, tortuous and possibly infinitely indefinable journey in making sense of the matter. I am confident that much will continue to evolve but I am also sure that a good deal of the process entailed is unnecessarily arduous and self-serving. I am equally sure that in due course, when everyone can be honest, there will be no genuine progress until funding and other resources are properly and openly admitted as necessary and provided either by state, transparent patient charges or other mechanisms.

The consultation paper and the accompanying statutory instrument run to 21 pages, which may not seem a lot but they took me a goodly time to read, comprehend and digest (I suggest downloading and printing them as one refers to the other) and required a revisit to really get my head around the proposals. I assume that under the current regulations I can count this as non-verifiable time spent but in future that will not be CPD as we know it.

\footnotetext{
. The GDC (Continuing Professional Development) (Dentists and Dental Care Professionals) Rules Order of Council. 2013 Consultation \& Statutory Instrument. www. gdc-uk.org/GDCcalendar/Consultations/ Pages/CPD-Rules-Consultation.aspx
}

DOI: 10.1038/sj.bdj.2014.102 